\title{
O ENSINO DA CULTURA INDÍGENA NA EDUCAÇÃO BÁSICA POR MEIO DA DANÇA
}

\section{TEACHING ABOUT INDIGENOUS CULTURE AT BASIC SCHOOL BY DANCING}

\section{LA ENSEÑANZA DE LA CULTURA INDÍGENA EN LA EDUCACIÓN BÁSICA ATRAVÉS DE LA DANZA}

\author{
Suselaine Ap. Zaniolo Mascioli \\ Pós doutora em Educação pela Universidade Federal de São Carlos - UFSCAr \\ Membro dos seguintes Grupos de pesquisa: GEERERE- Fundação Araporã; NEEVY - \\ Estudos em Vygotsky. Profa Orientadora do Pet Pedagogia - MEC/SESu \\ Docente das Faculdades Integradas de Jaú \\ E-mail:susezan@bol.com.br \\ Natália Mazzilli Dias \\ Graduada em Pedagogia pela Faculdade de Ciência e Letras - Unesp Araraquara. \\ Membro do grupo Pet Pedagogia - MEC/SESu e do GEERERE - Fundação Araporã \\ E-mail: namadias@hotmail.com
}

\section{RESUMO}

Este artigo possui como tema o ensino das Danças Indígenas na Educação Básica. A temática vem do interesse das pesquisadoras pela dança e da compreensão da dança enquanto manifestação cultural e patrimônio histórico-cultural das sociedades, e portanto das Danças Indígenas enquanto representação de luta e resistência na sociedade brasileira. Tem por objetivo, compreender as possibilidades de inserção das Danças Indígenas na Educação Básica como metodologia para o trabalho acerca das culturas e artes indígenas. Intentamos que este estudo subsidie a prática de professoras, de modo a enriquecer a atuação docente em relação às corporeidades e às relações étnico-raciais.

Palavras-chave: Dança na escola; Danças Indígenas; Educação Étnico-racial.

\begin{abstract}
This article has as its theme the teaching of Indigenous dances in Basic Education. The theme comes from the researchers' interest about dance and the understanding of dance as a cultural manifestation and historical-cultural heritage of societies, and therefore of Indigenous Dances as a representation of indigenous' struggle and resistance in Brazilian society. It aims to understand the possibilities of insertion of Indigenous Dances in Basic Education as methodology for the work with indigenous cultures and arts. We intend that this study subsidizes the practice of teachers, in order to enrich the teaching performance in relation to movement and ethnic-racial relations.
\end{abstract}

Key words: Dancing at school; Indigenous Dances; Ethnic-racial education. 


\section{RESUMEN}

Este artículo tiene como tema la enseñanza de Danzas Indígenas en Educación Básica. El tema proviene del interés de los investigadores en la danza y la comprensión de la danza como una manifestación cultural y patrimonio histórico-cultural de las sociedades, y por lo tanto de las Danzas Indígenas como una representación de la lucha y la resistencia en la sociedad brasileña. Su objetivo es comprender las posibilidades de inserción de las danzas indígenas en la educación básica como metodología para el trabajo sobre las culturas y artes indígenas. Pretendemos que este estudio subsidie la práctica de los docentes para enriquecer el desempeño docente en relación con las corporeidades y las relaciones étnico-raciales.

Palavras clave: Danzas en la escuela; Danzas indígenas; Educación étnico-racial

\section{DANÇA NA ESCOLA: DEFINIÇÃO E LEGISLAÇÃO}

O desenvolvimento deste estudo foi realizado no sentido de compreender o espaço que a dança e as culturas indígenas possuem na Educação Básica, e de que forma esses conteúdos podem relacionar-se entre si. É de suma importância, portanto, compreender os objetivos e competências da Educação Básica. Nesse sentido, fazemos a defesa de que o ensino, na educação escolar, deve ser priorizado no sentido de promover a aprendizagem dos alunos, pois, é a aprendizagem que provoca o seu desenvolvimento psíquico.

A partirdesta compreensão, é evidente que o trabalho da educação escolar deve ser o de promover a socialização dos indivíduos de maneira intencional e planejada, ou seja, dar a eles o acesso à cultura da sociedade em que estão inseridos da maneira mais ampla possível.

Para isso, é necessário que o aluno aproprie-se das diversas habilidades, construções sociais, normas de conduta e manifestações culturais - entre elas a arte em suas diferentes linguagens expressivas - que foram desenvolvidas pela sociedade ao longo dos séculos da história humana, sendo o papel da escola fundamental em tal processo.

\footnotetext{
A arte na forma da dança faz parte das culturas humanas e integra o trabalho, as religiões e atividades de lazer. Toda ação humana envolve a atividade corporal. A criança é um ser em constante mobilidade e utiliza-se dela para buscar conhecimento de si mesma e daquilo que a rodeia, relacionando-se com objetos e pessoas. (MASCIOLI, 2016, p. 73).
}

Em consonância com Mascioli (2016) cabe a escola preparar o aluno para uma leitura de mundo permeada por uma concepção de criticidade, e expressividade por meio das diferentes linguagens artísticas como a dança, música, pintura, etc. 
Mascioli (2016) reitera os pressupostos sobre a dança que se encontram dispostos nos Parâmetros Curriculares Nacionais de 1997 sobre a dança, reconhecendo a mesma como uma forma de integração e expressão, individual e coletiva, em que a criança exercita a atenção, percepção, colaboração e solidariedade. Uma atividade lúdica que permite a experimentação e criação, exercitando a espontaneidade; contribui ainda para o seu desenvolvimento, construindo sua imagem corporal, que são aspectos fundamentais para seu crescimento individual e consciência social.

Para promover esta aprendizagem desejável, os mecanismos de educação não devem se pautar naquilo que o aluno já conhece, por conta de seu cotidiano ou interesse natural. Segundo Mukhina (1996), o cotidiano é o que ocorre de maneira espontânea ao redor da criança, e não o que se propõe a efetivamente promover o seu desenvolvimento. Tendo isto em vista, compreende-se que aquilo que se pauta no cotidiano é restrito, não alcança o maior nível de conhecimento produzido pela humanidade.

A dança "promove o desenvolvimento das habilidades motoras, afetivas e cognitivas do aluno, além de estimular a inteligência, a autonomia, a responsabilidade e a sensibilidade ((MASCIOLI,2016, p.73). A arte na forma da dança faz parte das culturas humanas desde suas primeiras manifestações:

Desde que existe o homem, existe a dança. Antes mesmo de existir dança o homem já se usava o movimento corporal para expressar seus sentimentos. Uniu-se a música ao gesto, descoberto o som, o ritmo e o movimento, nasceu a dança. É uma das mais antigas artes criadas pelo homem, onde se manifestava todos os seus impulsos, crenças e desejos. A dança desde seu surgimento até a atualidade estampa uma linguagem corporal moldurada e inserida sob influência dos contextos econômicos, sociais, políticos e religiosos. (MASCIOLI,2016, p.71).

Enquanto arte e componente do repertório cultural da maioria das sociedades, produzida ao longo dos séculos e importante instrumento de manutenção cultural, a dança é uma prática indispensável na educação escolar para a promoção da aprendizagem dos alunos.

Essa prática está, inclusive, prevista em lei, desde 2016:LEI No 13.278, DE 2 DE MAIO DE 2016.

Altera o $\S 6$ o do art. 26 da Lei no 9.394, de 20 de dezembro de 1996, que fixa as diretrizes e bases da educação nacional, referente ao ensino da arte. [...]§ 6o As artes visuais, a dança, a música e o teatro são as linguagens que constituirão o componente curricular de que trata o $\S 20$ deste artigo. (BRASIL, 2016). 
Para a realização dessa aprendizagem, e consequentemente do desenvolvimento de seus alunos, é preciso que haja a mediação do professor entre o conhecimento e o aluno. Essa mediação pressupõe, portanto, que o professor compreenda a importância do ensino de dança e aproprie-se das possibilidades de realização desse ensino, de forma a enriquecer seu fazer docente. Nosso intento é, portanto, enriquecer o repertório de professores e trazer à tona a discussão da dança na escola, que vai além da "expressão" e "diversão", como está presente no discurso de senso comum. Segundo Isabel Marques (2012):

O fazer-sentir dança enquanto arte nos permite um tipo diferenciado de percepção, discriminação e crítica da dança, de suas relações conosco mesmos e com o mundo. Ao contrário do que nos oferece o senso comum, a dança não é um amontoado de emoções que permite que nos "autoexpressemos", "desanuviemos as tensões", sintamos o íntimo da alma". Isto não quer dizer que o trabalho com a dança não envolva as emoções, os sentimentos, a sensibilidade. A dança, como forma de arte, está engajada com o sentimento cognitivo e não somente com o sentimento afetivo - ou a liberação de emoções. Em nossos corpos, dançando, os sentimentos cognitivos se integram aos processos mentais para que possamos compreender o mundo de forma diferenciada, ou seja, artística e estética. (MARQUES, 2012, p. 28).

O ensino de dança na escola tem potencial para promover o desenvolvimento dos alunos no que diz respeito à formação da personalidade e às habilidades psíquicas superiores de atenção, concentração e imaginação. Além disso, a dança contribui para que as crianças desenvolvam consciência corporal e, enquanto dançam, experimentem estados mentais agradáveis. No que diz respeito à seleção das danças a serem ensinadas, entretanto, esse ensino pode ir muito além da experimentação prática em si.

É possível, com base em um ensino planejado e crítico, desenvolver questões políticas e culturais concomitantemente ao ensino prático da dança, o "educar pela dança" (MARQUES, 1996).

A partir das discussões acerca das diferentes culturas e, consequentemente, diferentes danças que permeiam o Brasil na atualidade, acreditamos que a dança é uma forma relevante de expressividade humana e que deve servir como subsídio para o ensino das relações étnicoraciais e o respeito à diversidade.

\section{AS CULTURAS INDÍGENAS NA ESCOLA}


Afim de promover o ensino pela dança que possibilite a discussão acerca das relações étnico-raciais e da diversidade, intentamos refletir sobre a temática indígena e sua inserção nesse âmbito.

É sabido que as culturas indígenas, importantes componentes da cultura brasileira desde os mais remotos tempos, ainda são pouco ou nada conhecidas pelos alunos da educação regular brasileira, apesar do fato de que o estudo da história e da cultura indígena na escola já estar regulamentado pela Lei Federal no 11.645/2008 que cria a obrigatoriedade do ensino da história e da cultura dos povos indígenas nos estabelecimentos de ensino fundamental e médio do país. Areferida Lei que altera a Lei n $\mathrm{n}^{\circ}$ 9.394, de 20 de dezembro de 1996, modificada pela Lei $\mathrm{n}^{\circ} 10.639$, de 9 de janeiro de 2003, que estabelece as diretrizes e bases da educação nacional, para incluir no currículo oficial da rede de ensino a obrigatoriedade da temática "História e Cultura Afro-Brasileira e Indígena".

\begin{abstract}
"Art. 26-A. Nos estabelecimentos de ensino fundamental e de ensino médio, públicos e privados, torna-se obrigatório o estudo da história e cultura afrobrasileira e indígena. $\S 1^{\circ} \mathrm{O}$ conteúdo programático a que se refere este artigo incluirá diversos aspectos da história e da cultura que caracterizam a formação da população brasileira, a partir desses dois grupos étnicos, tais como o estudo da história da África e dos africanos, a luta dos negros e dos povos indígenas no Brasil, a cultura negra e indígena brasileira e o negro e o índio na formação da sociedade nacional, resgatando as suas contribuições nas áreas social, econômica e política, pertinentes à história do Brasil. $\S 2^{\circ}$ Os conteúdos referentes à história e cultura afro-brasileira e dos povos indígenas brasileiros serão ministrados no âmbito de todo o currículo escolar, em especial nas áreas de educação artística e de literatura e história brasileiras." (BRASIL, 2008).
\end{abstract}

Observa-se na Lei os esforços que vem sendo historicamente empreendidos para concretizar um diálogo intercultural que faça uso dos espaços escolares e de propostas educacionais.

Podemos dizer que os movimentos que visam a escolarização, bem como a recente, porém intensa presença de estudantes indígenas nas universidades, fazem parte de uma luta mais ampla dos povos originários em toda a América, que escolheram a educação escolar como uma aliada nas suas políticas de afirmação étnica, bem como para o diálogo com outras sociedades. (BERGAMASCHI E GOMES,2012, p.55).

Uma vez explicitada a compreensão da necessidade do ensino de dança nas diferentes etapas da Educação Básica, bem como da necessidade do ensino e da discussão das culturas 19 
indígenas presentes no Brasil, parece-nos primordial a proposta da inserção das danças indígenas no trabalho de professores da Educação Básica.

Para a realização dessa proposta, é preciso compreender do que se tratam as Danças Indígenas. Antes de quaisquer apontamentos, é imprescindível a compreensão de que não existe uma "cultura indígena", menos ainda uma "dança indígena".

Atualmente, no Brasil, segundo o Censo Demográfico de 2010, em 80,5\% dos municípios brasileiros há pelo menos um indígena auto declarado (IBGE, 2012). Esse dado indica que as diferentes etnias indígenas estão espalhadas pelo país, e visto que possuem cada uma a sua cultura, seus rituais, suas danças e sua história própria, a diversidade é grande.

Tal fato nos leva a necessidade que buscamos estratégias pedagógicas que rompam imagens estereotipadas que a sociedade em geral - e por consequência, os alunos presentes na educação Básica- associam aos indígenas e, que nos permitam legitimar os saberes indígenas na escola.

A título de estudo, o recorte que se fez presente neste artigo, buscou, identificar e reunir pontos em comum, que se manifestam na maioria das etnias indígenas, de maneira que o trabalho docente acerca das Danças Indígenas pudesse ter um parâmetro e algumas primeiras aproximações. É importante, entretanto, que a temática indígena a ser ensinada para os alunos da Educação Básica tenha este alerta: o de que as culturas indígenas são múltiplas.

\section{AS DANÇAS INDÍGENAS: ANÁLISES}

De acordo com as leituras realizadas, entretanto, foi possível identificar alguns pontos comuns nas Danças Indígenas: em sua grande maioria, são associadas aos acontecimentos importantes da tribo, rituais, seja comemorativo ou em tom de lamento e, localizada em cerimonias sagradas,normalmente associadas, às músicas, pinturas corporais, comidas e outras formas de expressões artísticas. Pode assim, ter como intenção o agradecimento às colheitas, marcar a passagem de idade do jovem à fase adulta, saldar quem chega a aldeia, etc.

Além disso, as Danças indígenas frequentemente se relacionam com a questão da natureza, da terra, do clima e das colheitas, ou seja, das questões de seu cotidiano. Segundo Lúcia Gaspar (2011): 
O índio dança para celebrar atos, fatos e feitos relativos à vida e aos costumes. Dançam enquanto preparam a guerra; quando voltam dela; para celebrar um cacique, safras, o amadurecimento de frutas, uma boa pescaria; para assinalar a puberdade dos adolescentes ou homenagear os mortos em rituais fúnebres; espantar doenças, epidemias e outros flagelos. (GASPAR, 2011).

Segundo Artaxo (2003) as danças indígenas basicamente se apresentam em um compasso binário (dois tempos) para marcar o ritmo da dança e da música. Cada dança indígena apresenta porém, um significado, uma história representada pelo movimento corporal. Executada por um único individuo ou em grupo e, raramente (salvo alguns grupos localizados no alto Xingu), é executada em pares de homens e mulheres.

Regina Müller, antropóloga pesquisadora das Danças Indígenas, realizou um trabalho no qual se propôs analisar os rituais e danças dos Asuriní, no Xingú. Em seu artigo "Danças indígenas: arte e cultura, história e performance", a autora descreve 3 danças: o ritual xamanístico Maraká, o ritual cosmogônico das flautas Turé (Toré), e a dança das mulheres Tauva.

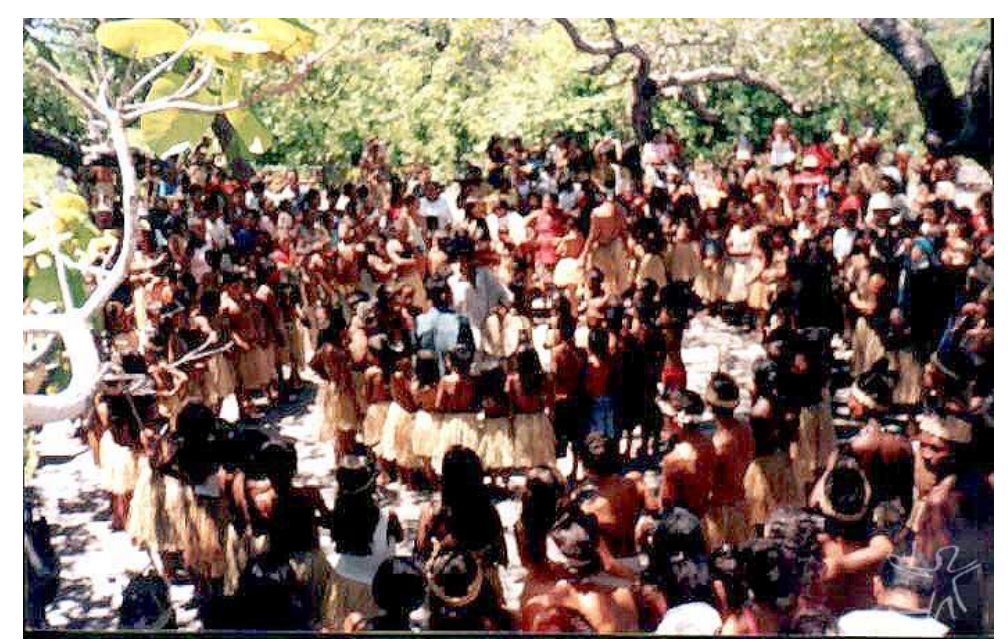

Roda do Toré - FONTE: https://pib.socioambiental.org/pt/povo/potiguara/941

A pesquisadora observou essas danças no contexto histórico e cultural no qual estão inseridas, mas também enquanto manifestação estética.

As sensações de "suspensão/boiar" e a de "deixar cair/afundar" associadas às qualidades do movimento (Laban) propiciam experiências psicossomáticas passíveis de observação nas ações corporais e que são, ainda, experiências do significado da noção coexistência dos seres em diferentes planos cósmicos, presença dos espíritos entre os humanos e viagens dos xamãs a outros mundos do cosmo. A alternância das ações - "socar" e "deslizar" - que resulta da análise como marca formal deste discurso não-verbal, cuja 
organização em torno de objetos semânticos, as sensações de "suspensão" e "deixar cair" se dá como tensão. Dança-se "deslizando", no convive aos espíritos para virem participar, tomar junto o mingau, fumar o charuto de tabaco. Dança-se com movimento forte, rápido, "socando", na forma agressiva de se tirar a causa da doença do corpo dos pacientes. (MÜLLER, 2004, p. 132).

Segundo as descrições da autora, essas danças são realizadas por homens e mulheres, mas existem papéis distintos de acordo com o gênero. Além disso, os sujeitos na dança tocam instrumentos ao mesmo tempo (como é o caso das flautas Turé, por exemplo, que apresentavariações de ritmos e toadas dependendo de cada povo e é considerado o símbolo maior de resistência e união entre os povos indígenas.

Para Müller (2004) essas danças fazem referência à presença de espíritos e à relação entre os indígenas vivos e os espíritos - entre "este lado" e "aquele lado" -, que possuem poder da cura mas também representam perigo, conforme Müller destaca:

Este conjunto de elementos coordenados de acordo com um script, uma estrutura, uma forma e um estilo, permitem a experiência estética e sinestésica de uma convivência necessária: a convivência com os espíritos, com o outro, em outra dimensão da realidade. (MÜLLER, 2004, p. 129).

O "script" a que a autora se refere é algo a ser destacado nessas danças: a alusão que fazem à histórias do povo, inclusive histórias mitológicas. Os rituais se baseiam em histórias que são contadas ao longo das gerações, sobre guerreiros e guerras, sobre as vitórias e as derrotas vividas pelo povo Asuriní e,portanto as danças possuem um roteiro, semelhante ao que seria uma peça teatral, porém dançada:

A transformação (ou transportação) do artista performático e do xamã é o ponto de convergência entre os dois gêneros de "performance cultural" tal como se designa aqui as artes cênicas (dança e teatro) e o ritual. Outras aproximações em que a abordagem se apoia é o processo de se compartilhar coletivamente a experiência individual, como ocorre em ambas manifestações e a refletividade constitutiva destes gêneros, proporcionada pelo estado subjuntivo. (MÜLLER, 2004, p. 129).

De acordo com os apontamentos da autora, esse caráter teatral dos rituais realiza o papel de transmitir histórias e ensinamentos da etnia ao longo das gerações, tornando coletivas as memórias individuais e individualizando as memórias coletivas. A autora cita, inclusive, uma dança que marca a puberdade dos meninos desse povo. Nessa tradição, os 
meninos têm algum sonho, e devem compartilhar esse sonho com seus colegas, para que possam encenar o sonho que este jovem teve.

É possível observar, nessa narração, a prática de que cada indivíduo indígena experimenta em seu próprio corpo as experiências do outro, assim como a história, a movimentação, o canto e a dança produzidos em outros contextos de seu povo. Segundo Müller, essa prática está "relacionada aos princípios, como vimos, de continuidade cultural, social e de sua própria sobrevivência, promovendo sentimento de coletividade e de conexão com os seres imortais" (MÜLLER, 2004, p. 135).

Outro exemplo que podemos citar em nossa análise é a 'Dança da Ema', que se apresenta na Cultura Terena e tem sido transmitida pelas gerações. Também é conhecida pelos não indígenas como a 'Dança do Bate-pau', por utilizar em sua performance varas de taquara ou bambu.

A referida dança é executada por homens de várias idades, de crianças a idosos ${ }^{1} \operatorname{como}$ podemos observar nas fotografias abaixo (arquivo pessoal) registradas durante visita à aldeia Ekeruá Localizada no Municipio de Avaí - SP:

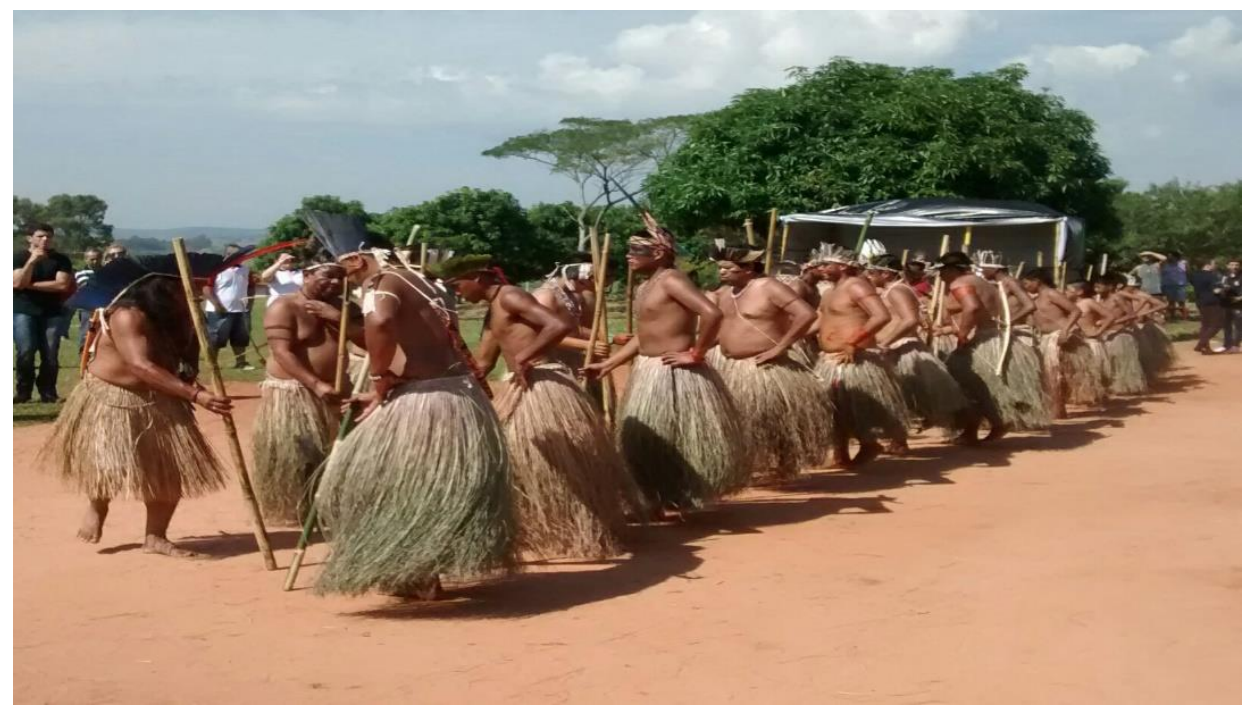

${ }^{1}$ Durante a Dança da Ema toca-se flauta e tambor para dar o ritmo aos passos dos dançarinos. As cores do ritual são vermelha, azul e branca. As vestes de pena de ema e de palha são especialmente preparadas para essa dança, para esse ritual. Os homens carregam longas taquaras nas mãos e com elas desenvolvem umacoreografia, ora batendo as taquaras com as de outros dançarino, ora batendo-as no chão. O final da dança é marcado pela reunião dos dançarinos em círculo e a união das taquaras, sobre as quais é colocado um guerreiro, que é então erguido e ovacionado. FONTE:http://pibidletrascpaq.blogspot.com.br/2015/08/a-danca-do-bate-pauuma-cultura-que.html 


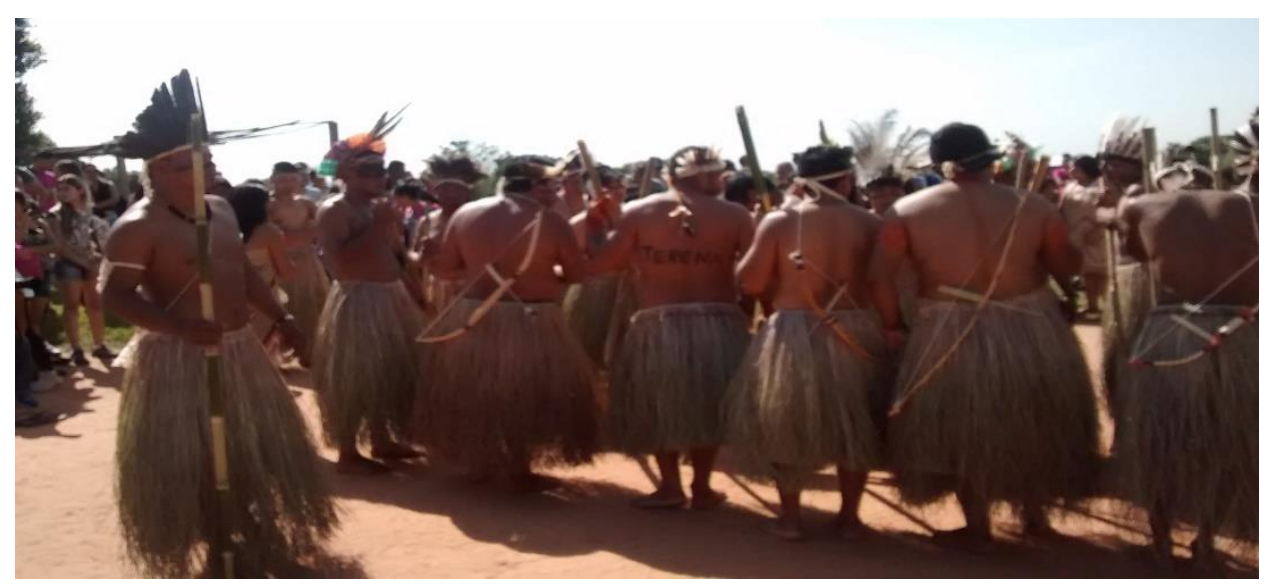

Segundo o antropólogo Antenfelder (2000) o povo Terena, possui uma trajetória histórica de constantes deslocamentos e enfrentamentos permeados pela força, coragem e garra. E, suas danças tradicionais mantiveram esses elementos presentes até os dias atuais.

Antenfelder (2000) aponta ainda para a relevância da pintura Terena nas danças e festas. Segundo ele, a pintura do corpo em forma de riscas em branco e preto era feita da resina do jenipapo e carvão vegetal. "Os desenhos são feitos de uma excessiva fineza e apresentam uma harmonia e delicadeza que é impossível de se descrever" (ANTENFELDER, apud BITTENCOURT e LADEIRA, ano 2000, p.110).

E naquele tempo, quando terminou a guerra do Paraguai, as pessoas que começaram a se juntar de novo ficaram alegres e este é o Bate-Pau, vermelho contra azul. E este azul começou a se manifestar de alegria. Por isso criaram a bandeira azul dos purutuyé. E esse vermelho é o sangue de nossos avós, dizia meu avô. Por isso nós ganhamos nossa terra. Por causa dos sangue de nossos avós. Então por isso que os dois cabeças do Bate-Pau se perguntam: 'e daí... nós vamos brigar?' e respondem: 'Não. Nós vamos brincar e começar a ficar alegres!. disseram os lados azul e vermelho' (João Martins Menootó apud BITTENCOURT e LADEIRA, ano 2000, p.149).

A noção de continuidade cultural é imprescindível nas práticas indígenas e nas discussões acerca da temática indígena. Isto porque suas histórias, culturas e mesmo vidas estão constantemente ameaçadas no Brasil, atualmente e desde tempos remotos, no período de nossa colonização. Os rituais são, portanto, sobretudo uma estratégia de manutenção e de resistência desses povos, que vivem em todos os cantos do país, uma vez que é por meio desses rituais que os novos indígenas apropriam-se da cultura de seu povo, e é nisto que sua cultura se solidifica. 


\section{DANÇAS INDÍGENAS NA ESCOLA: PROPOSTAS METODOLÓGICAS}

Levando em consideração os apontamentos realizados, indicamos neste estudo uma proposta metodológica que considere o ensino das Danças Indígenas nas diferentes etapas da Educação Básica, buscando atingir os objetivos de ensino de dança, bem como o objetivo de educação para as relações étnico-raciais.

Em razão da pluralidade de culturas e danças indígenas, consideramos interessante que o professor desenvolva atividades que permitam aos alunos compreender essa multiplicidade isso pode ser realizado, por exemplo, sugerindo que cada grupo de alunos pesquise por danças ou rituais de etnias diferentes, de maneira que a classe, como um todo, visualize essas diferenças conjuntamente.

Outro aspecto importante destacado nos rituais indígenas é o fato da continuidade cultural e da memória coletiva a que estão relacionados. Essas são reflexões importantes a serem feitas com os alunos: as lutas que os povos indígenas precisaram travar, as batalhas à que foram submetidos, as suas estratégias de resistência, as suas crenças e as histórias nas quais as danças se fundamentam, bem como os significados dessas histórias.

Entendemos que esse exercício permitirá que os alunos ampliem seu repertório cultural, o que promoverá a aprendizagem, e também o desenvolvimento do senso de cidadania e respeito pelas diversidades. Lembramos que é papel da educação desenvolver cidadãos que compreendam as diferenças entre as culturas vivas atualmente, e respeitem essas diferenças.

Finalmente, acreditamos também ser imperativo a prática efetiva da dança e da experimentação de alteridade, isto é, a vivência, no próprio corpo, das experiências vividas por outras pessoas, em outros contextos históricos e sociais. Essa relação com a alteridade está presente nas danças indígenas, no tocante à história de seus antepassados, e também deve estar presente na educação escolar, no que diz respeito à cultura indígena, que é alheia aos alunos que não pertencem às etnias indígenas.

Para realizar essa proposta, o professor poderá sugerir que os alunos estudem histórias que dizem respeito a sua própria descendência. Podem ser histórias de seu bairro, de sua cidade ou mesmo mitos ou fábulas acerca da história do país. Dessa forma, os alunos podem, com a mediação do professor, elaborar uma dança (na qual pode ser incluso, bem como nas danças indígenas, o canto, os instrumentos e a dramatização) que represente essa história. 


\title{
CONCLUSÃO
}

\begin{abstract}
Então é nesse sentido que eu acho que a arte contribui muito para desenvolver o sentido de cidadania, atentar para diversidade cultural, para começar a respeitar as diferenças entre grupos culturais. [...] Eu acho que através da arte, através inclusive... Mas depende aí do professor. Ele tem que ter uma escolha muito diversificada, não adianta só dar o código europeu e norte-americano branco na escola. Você tem que procurar a arte feita pelas mulheres, pelos índios, pelos negros, e tentar discutir isso com seus alunos, mostrar a validade, a importância cultural de cada uma daquelas manifestações, sem preponderância de uma sobre a outra. E aí você terá um panorama cultural de seu país. Se você conhece culturalmente o seu país, você tem mais chance de respeitá-lo, e isso para mim é cidadania. (BARBOSA, 1998).
\end{abstract}

Este estudo procurou balizar a relação entre dança - enquanto linguagem artística e expressiva - e cultura. Por isso, compreendemos ser indispensável o ensino de danças indígenas na Educação Básica, de forma a auxiliar os alunos na apropriação acerca dessas culturas componentes e fundamentais na história brasileira, e de formá-los crítica e politicamente sobre a história e a realidade atual desses povos.

O ensino com base na experimentação corporal, isto é, pela dança, permite que os alunos possuam maior aproximação com o tema. É importante também que os educandos vivenciem essa relação de alteridade, uma vez que as realidades indígenas muitas vezes parecem distantes do ambiente escolar.

Esperamos assim contribuir para a contextualização das manifestações artísticas como produtos culturais de um povo e de uma época; respeitar etnias e culturas diferentes e, auxiliar os professores para que realizem atividades que enriquecerão seu ensino e auxiliarão na formação de cidadãos culturalmente formados, políticos e críticos.

\section{REFERÊNCIAS BIBLIOGRÁFICAS}

ARTAXO, Maria Inês. Ritmo e movimento. Guarulhos: Phorte Editora, 2003.

BARBOSA, Ana Mae. Memória Roda viva. TV Cultura: 1998. Disponível em:<http://www.rodaviva.fapesp.br/materia/370/entrevistados/ana_mae_barbosa_1998.htm> Acesso em: 03 mar. 2018.

BERGAMASCHI, Maria Aparecida e GOMES, Luana Barth. A TEMÁTICA INDÍGENA NA ESCOLA: ensaios de educação intercultural. Currículo sem Fronteiras, v.12, n.1, pp. 53-69, Jan/Abr 2012. 
BITTENCOURT, Circe Maria e LADEIRA, Maria Elisa. A história do povo Terena. Brasília: MEC, 2000.

BRASIL, Lei $\mathbf{N}^{\mathbf{0}}$ 11.645, de 10 de Março de 2008. Dispõe sobre as diretrizes e bases da educação nacional. Diário oficial da União. Brasília, DF, 10 mar. 2008. Disponível em: <https://www.planalto.gov.br/ccivil_03/_ato2007-2010/2008/lei/111645.htm> Acesso em: 03 mar. 2018.

BRASIL, Lei $\mathbf{N}^{\mathbf{0}}$ 13.278, de 2 de Maio de 2016. Dispõe sobre as diretrizes e bases da educação nacional. Diário oficial da União. Brasília, DF, 2 mai. 2016. Disponível em: <http://www.planalto.gov.br/ccivil_03/_ato2015-2018/2016/lei/113278.htm> Acesso em: 03 mar. 2018.

DAMASIO, Cláudia. A dança para crianças. In: PEREIRA, Roberto e SOTER, Silvia. Lições de Dança 2. Rio de Janeiro: UniverCidade, 2000.

GASPAR, Lúcia. Danças indígenas do Brasil. Pesquisa Escolar Online, Fundação Joaquim Nabuco, Recife. Disponível em: < http://basilio.fundaj.gov.br/pesquisaescolar/>. Acesso em: 03 mar. 2018.

IBGE, Os Indígenas no Censo Demográfico 2010: primeiras considerações com base no quesito cor ou raça. Rio de Janeiro, 2012.

MARQUES, Isabel. Dançando na escola. São Paulo: Cortez, 2012.

MASCIOLI, Suselaine A.Zaniolo. Conteúdo, Metodologia e Prática de Ensino da Arte. Rio de Janeiro: SESES, 2016.

MUKHINA, Valeria. Psicologia da idade pré-escolar. São Paulo: Martins Fontes, 1996. 312 p.

MÜLLER, Regina Polo. Danças indígenas: arte e cultura, história e performance. Indiana, n. 21, p. 127-137, 2004. Disponível em:

$<$ http://www.iai.spkberlin.de/fileadmin/dokumentenbibliothek/Indiana/Indiana_21/10Mueller $\underline{\text { RegPol neu-kM .pdf }}$ 